\title{
Plasma and Red Cell Reference Intervals of 5-Methyltetrahydrofolate of Healthy Adults in Whom Biochemical Functional Deficiencies of Folate and Vitamin $B_{12}$ Had Been Excluded
}

\author{
Agata Sobczyńska-Malefora, Dominic J. Harrington, Kieran Voong, and Martin J. Shearer \\ The Nutristasis Unit, The Centre for Haemostasis and Thrombosis, GSTS Pathology (Part of King's Healthcare Partners), \\ St. Thomas' Hospital, London SE1 7EH, UK \\ Correspondence should be addressed to Agata Sobczyńska-Malefora; agata.malefora@gsts.com
}

Received 22 July 2013; Revised 11 October 2013; Accepted 9 December 2013; Published 15 January 2014

Academic Editor: David Varon

Copyright (C) 2014 Agata Sobczyńska-Malefora et al. This is an open access article distributed under the Creative Commons Attribution License, which permits unrestricted use, distribution, and reproduction in any medium, provided the original work is properly cited.

\begin{abstract}
5-Methyltetrahydrofolate (5-MTHF) is the predominant form of folate and a strong determinant of homocysteine concentrations. There is evidence that suboptimal 5-MTHF availability is a risk factor for cardiovascular disease independent of homocysteine. The analysis of folates remains challenging and is almost exclusively limited to the reporting of "total" folate rather than individual molecular forms. The purpose of this study was to establish the reference intervals of 5-MTHF in plasma and red cells of healthy adults who had been prescreened to exclude biochemical evidence of functional deficiency of folate and/or vitamin $B_{12}$. Functional folate and vitamin $B_{12}$ status was assessed by respective plasma measurements of homocysteine and methylmalonic acid in 144 healthy volunteers, aged 19-64 years. After the exclusion of 10 individuals, values for 134 subjects were used to establish the upper reference limits for homocysteine $(13 \mu \mathrm{mol} / \mathrm{L}$ females and $15 \mu \mathrm{mol} / \mathrm{L}$ males) and methylmalonic acid $(430 \mathrm{nmol} / \mathrm{L})$. Subjects with values below these cutoffs were designated as folate and vitamin $\mathrm{B}_{12}$ replete and their plasma and red cell 5-MTHF reference intervals determined, $N=126: 6.6-39.9 \mathrm{nmol} / \mathrm{L}$ and $223-1041 \mathrm{nmol} / \mathrm{L}$, respectively. The application of these intervals will assist in the evaluation of folate status and facilitate studies to evaluate the relationship of 5-MTHF to disease.
\end{abstract}

\section{Introduction}

5-MTHF, the predominant form of folate (vitamin $\mathrm{B}_{9}$ ) in plasma and red cells, is a substrate for the methionine synthase and vitamin $\mathrm{B}_{12}$ (methylcobalamin form-methyl$\mathrm{Cbl}$ ) mediated conversion of homocysteine (tHcy) to methionine (Figure 1). Suboptimal 5-MTHF availability leads to an increase in circulating homocysteine (hyperhomocysteinaemia) which has been associated with many diseases and health complications including cardiovascular disease $[1,2]$. There is also evidence to suggest that 5-MTHF deficiency may be a cardiovascular risk factor independent of homocysteine $[3,4]$.

In the plasma of healthy humans, 5-MTHF typically constitutes $80-90 \%$ of total folate $[5,6]$. Circulatory concentrations of 5-MTHF are partly dependant on methylenetetrahydrofolate reductase (MTHFR) genotype [7, 8]. Conversely, the 5-MTHF content of red cells has been reported to vary greatly $[9,10]$.

Tissue folate status is typically assessed by measurement of "total" folate concentration in blood because commonly available assays are unable to differentiate between the various circulatory forms. Analysis of folate in red cells is considered to be a strong indicator of folate adequacy because it reflects intracellular status and is not influenced by recent or transient changes in dietary folate intake. Traditionally a value of $317 \mathrm{nmol} / \mathrm{L}(140 \mu \mathrm{g} / \mathrm{L})$ for red cell folate (RCF) has been considered as the cutoff concentration for folate adequacy [11]. Serum levels $<7.9 \mathrm{nmol} / \mathrm{L}(<3 \mu \mathrm{g} / \mathrm{L})$ usually indicate folate insufficiency. However, there is little consensus for the reference intervals for plasma and red cell folate [12]. 


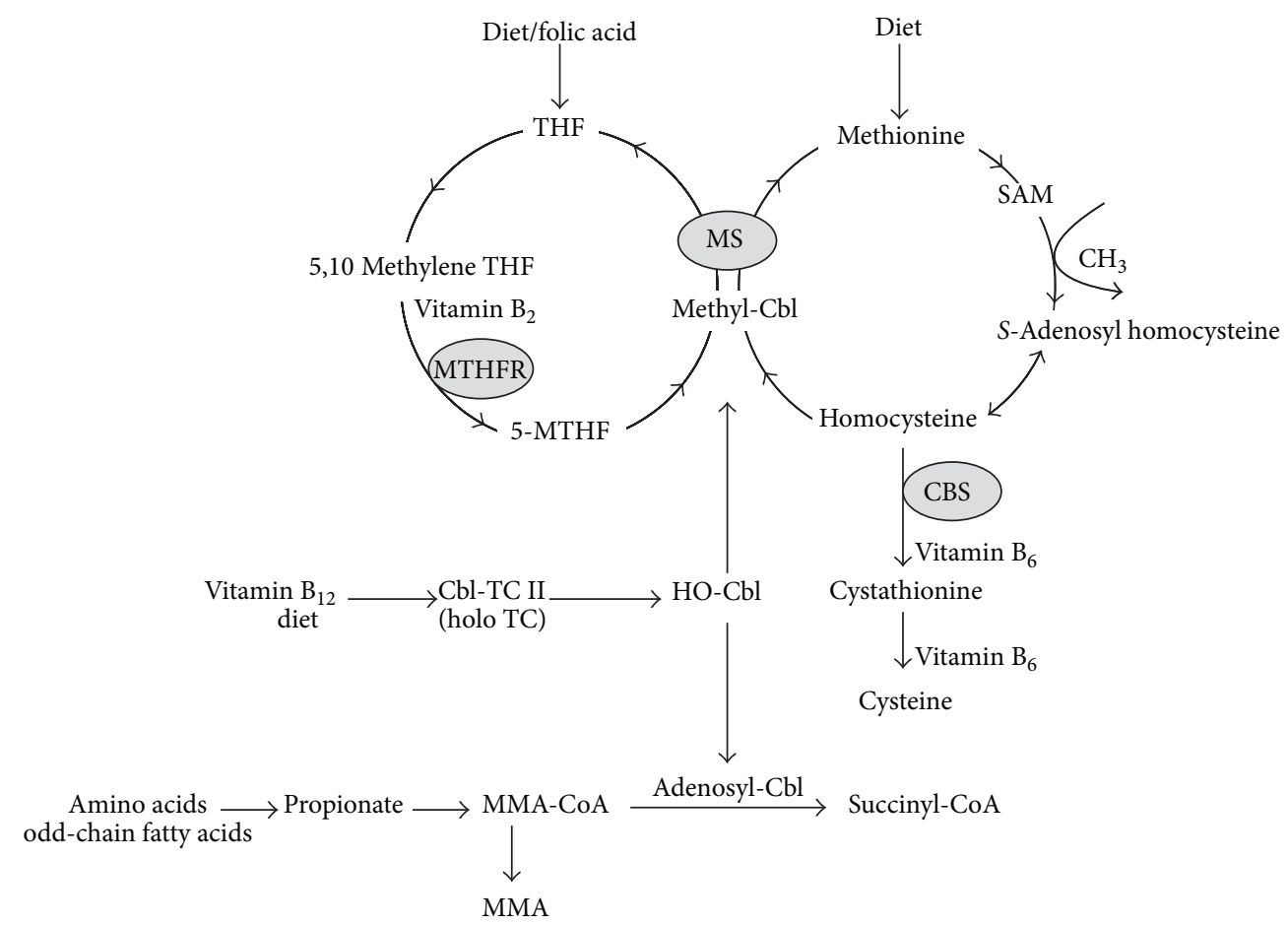

FIGURE 1: Homocysteine, folate, and vitamin $\mathrm{B}_{12}$ metabolism. THF (tetrahydrofolate), 5-MTHF (5-methyltetrahydrofolate), MTHFR (methylene tetrahydrofolate reductase), MS (methionine synthase), CBS (cystathionine beta-synthase), SAM (S-adenosyl methionine), Cbl (cobalamin), TC II (transcobalamin), holo TC (holotrascobalamin), OH-Cbl (hydroxocobalamin), MMA-CoA (methylmalonyl-CoA), and MMA (methylmalonic acid).

Furthermore, methodology bias is very common in folate assays and particularly pronounced for RCF values, as a consequence of variation in approach to the preparation and storage of red cell lysates [12]. This lack of harmonisation of folate methods prevents the interlaboratory adoption of reference intervals.

The purpose of this study was to establish reference intervals for plasma and red cell 5-MTHF in adults, using a fully validated HPLC assay, after excluding subjects in whom functional folate and/or vitamin $B_{12}$ deficiency was biochemically indicated by elevated concentrations of tHcy and/or MMA, respectively. The basis of an elevated MMA concentration as a sensitive functional indicator of vitamin $B_{12}$ deficiency is that 5-deoxyadenosylcobalamin is an essential cofactor for the conversion of methylmalonyl-CoA to succinyl-CoA. In vita$\min B_{12}$ insufficiency/deficiency (5-deoxyadenosylcobalamin form) the excess of methylmalonyl-CoA is hydrolysed to MMA causing the circulatory concentration of MMA to increase (Figure 1) [13].

\section{Materials and Methods}

2.1. Study Participants and Study Design. One hundred and forty-four volunteers, aged 19-64 years, were recruited from members of staff from St. Thomas' Hospital by advertisement. Subjects were excluded from participation if they were pregnant or taking vitamin supplements or drugs (e.g., phenytoin) known to interfere with folate or homocysteine metabolism. Recruited subjects were then screened to assess their functional folate and vitamin $B_{12}$ status. This led to the exclusion of ten subjects who had either outlying values of tHcy and/or MMA or who admitted to previously undeclared use of relevant dietary supplements and/or drugs. Of the remaining 134 subjects, those with tHcy and MMA values above their respective 97.5 th percentiles were deemed to be potentially folate or vitamin $B_{12}$ deficient and were excluded from our reported reference intervals for 5-MTHF. The study was approved by St. Thomas' Hospital Local Research Ethics Committee and written consent was obtained from all participants.

2.2. Blood Collection and Analytical Methods. Nonfasting, venous blood samples were collected into EDTA-containing tubes and immediately placed on ice and protected from light. Following hematocrit determinations, lysates were prepared by the addition of $100 \mu \mathrm{L}$ whole blood to $900 \mu \mathrm{L}$ of $5 \mathrm{~g} / \mathrm{L}$ ascorbic acid solution. Plasma was prepared by centrifugation. All samples were stored at $-70^{\circ} \mathrm{C}$ until analysis.

Plasma tHcy was measured by automated fluorescence polarization immunoassay (IMx, Abbott Laboratories). The intra- and inter-CVs for this assay were $2.0 \%$ and $2.7 \%$, respectively. Plasma MMA was analysed using HPLC [14]. The differences of duplicate analysis of 16 samples ranged from 0.0 to $10.9 \%$, while the interassay CVs for five samples (concentration range: $177-1114 \mathrm{nmol} / \mathrm{L}$ ) were between 6 and $12 \%$. 
Plasma and red blood cell 5-MTHF were measured by HPLC as previously described [15]. In brief, 4-aminoacetophenone was used as an internal standard [16] and Bond Elut $\mathrm{C}_{18}$ (100 mg, $1 \mathrm{~mL}$ reservoir) cartridges (Varian Inc.) were utilised for SPE with an elution strategy based on that of Pfeiffer et al. [6] with some in-house modifications. Sample components were separated using a ACE $\mathrm{C}_{18}, 3 \mu \mathrm{m}$ column $(125 \times 4.6 \mathrm{~mm})$ supplied by Hichrom, UK, with a mobile phase composition of $0.033 \mathrm{~mol} / \mathrm{L}$ potassium phosphate buffer ( $\mathrm{pH} 2.3$ ) : acetonitrile: methanol (89:6.6:4.4, by volume) at a flow rate of $0.34 \mathrm{~mL} / \mathrm{min}$. The fluorescence detector wavelength settings were: excitation $290 \mathrm{~nm}$ and emission $365 \mathrm{~nm}$.

A primary stock solution of 5-MTHF was prepared by dissolving $\sim 5 \mathrm{mg}$ of 5-MTHF powder in $10 \mathrm{~mL}$ of $20 \mathrm{mM}$ potassium phosphate buffer $\mathrm{pH} 7.2$ with $1 \mathrm{~g} / \mathrm{L}$ cysteine. An aliquot $(1 \mathrm{~mL})$ of this stock solution was removed to determine the concentration by UV spectrophotometry and $90 \mathrm{mg}$ of ascorbic acid powder was immediately added to the remaining stock solution. The absorbance of 5-MTHF was measured at $290 \mathrm{~nm}$ using the molar absorptivity value of $32000 \mathrm{~L} \mathrm{~mol}^{-1} \mathrm{~cm}^{-1}$ after 1 in 40 and 1 in 33.3 dilution with $20 \mathrm{mmol} / \mathrm{L}$ potassium phosphate buffer $\mathrm{pH} 7.2$ containing $1 \mathrm{~g} / \mathrm{L}$ cysteine.

The primary stock solution $(1018.70 \mu \mathrm{mol} / \mathrm{L})$ was diluted 1 in 5 in $10 \mathrm{~g} / \mathrm{L}$ ascorbic acid and this stock solution was aliquoted and stored at $-70^{\circ} \mathrm{C}$ (secondary stock: $203.74 \mu \mathrm{mol} / \mathrm{L}$ ). One aliquot of the secondary stock solution was diluted further with $1 \mathrm{~g} / \mathrm{L}$ ascorbic acid to the concentration of $20.37 \mu \mathrm{mol} / \mathrm{L}$ (tertiary stock). This stock was used on the day of analysis to prepare a calibration curve of a minimum of four points.

The accuracy of our 5-MTHF calibration standard was checked against the Standard Reference Material (SRM) 1955 (National Institute of Standards \& Technology, USA) which included three reference samples with certified 5-MTHF concentrations (uncertainties) of $4.26 \pm 0.25,9.73 \pm 0.24$, and $37.1 \pm 1.4 \mathrm{nmol} / \mathrm{L}$ [17]. These reference samples were used to construct a calibration curve to verify the 5-MTHF concentration of our secondary stock solution with the theoretical concentration (by UV spectroscopy) of $203.74 \mu \mathrm{mol} / \mathrm{L}$. The calculated concentration of our secondary stock using the SRM 1955 generated standard curve was $196.13 \mu \mathrm{mol} / \mathrm{L}(3.6 \%$ difference). In another analytical run the standard curve was prepared by serial dilutions of the $20.37 \mu \mathrm{mol} / \mathrm{L} 5-\mathrm{MTHF}$ tertiary stock (as in the typical HPLC run) and SRM 1955 samples were analysed. The CVs for the means derived from the values assigned by the manufacturer of SRM 1955 and obtained in these analyses ranged from 2.1 to $5.9 \%$ for samples with the concentration of 4.26 and $37.1 \mathrm{nmol} / \mathrm{L}$, respectively.

The 5-MTHF red cell folate concentration was calculated according to the formula

\section{5-MTHF in red cells}

$$
=\{\text { whole blood } 5-\mathrm{MTHF}
$$

$$
\text { - [plasma 5-MTHF (1 - hematocrit)]\} }
$$$$
\times \text { hematocrit }^{-1}
$$

$[4,18]$.

2.3. Statistical Analysis. Normality of data was checked by the Kolmogorov-Smirnov test. Where the variables were not normally distributed; nonparametric tests or $\log _{10}$ transformed values were used. Subjects with outlying tHcy, MMA, and 5MTHF values were excluded using the Tukey test $[19,20]$. For the lower (where appropriate) and upper reference limits the 2.5th and 97.5th percentiles were used. The $z$-test was used to establish whether to partition reference values by sex $[19,21]$. The independent samples Student's $t$-test was applied to compare the values between sexes. Confidence intervals for the lower and upper reference limits were obtained using the rank numbers [19, 22]. Pearson's or Spearman's correlations were carried out to examine relationships between two continuous variables. Results were considered statistically significant if the observed, two-sided $P$ value was $<0.05$. Statistical analyses were carried out using SPSS for Windows (SPSS Inc., USA).

\section{Results}

3.1. Screening for Subjects with Outlying tHcy and MMA Results and the 97.5th Percentiles for tHcy and MMA. Of the 144 subjects initially recruited, 72 (50\%) were represented by laboratory staff, 36 (25\%) held administrative positions, $24(16 \%)$ were from supporting services, and 12 (8\%) held clinical posts. The majority of participants were Caucasian $N=107$ (74\%), with 20 (14\%) of Asian and 17 (12\%) of AfroCaribbean origins. Ten of these subjects were excluded before the determination of the upper cutoff values for plasma tHcy and MMA. Three of these 10 subjects were taking vitamin supplements and one subject was taking opiates which are known to affect folate metabolism [23, 24]. Two subjects with tHcy $>15 \mu \mathrm{mol} / \mathrm{L}$, on further investigation, were found to be taking medication that interfered with tHcy metabolism [23, 25]. The remaining four subjects were identified as outliers (Tukey method). Two of these four subjects had an MMA $>1000 \mathrm{nmol} / \mathrm{L}$ (suggestive of vitamin $\mathrm{B}_{12}$ deficiency); one had a family history of pernicious anaemia whilst the other individual was on medications and consumed a vegetarian diet. One of these four subjects had a plasma tHcy of $25.7 \mu \mathrm{mol} / \mathrm{L}$ with low MMA (121 nmol/L) suggesting folate deficiency and in another both markers were elevated. To the best of our knowledge no other volunteers participating in the study were taking vitamins or any drugs/medications interfering with folate/homocysteine metabolism. The remaining 134 subjects were used to establish the upper cutoff values for tHcy.

Plasma tHcy was normally distributed $(P=0.348)$, whilst plasma MMA was positively skewed $(P=0.007)$. There was a gender difference in tHcy concentrations $(P=0.01)$ with males having higher values. Plasma MMA concentration did not differ between genders $(P=0.440)$. After the exclusion of the upper 2.5 th percentile, upper reference limits for 
TABLE 1: Summary of results of $N=126$ subjects used to derive 5-MTHF reference intervals.

\begin{tabular}{lcccc}
\hline & $\begin{array}{c}\text { Females } N=69 \text { mean } \\
(\mathrm{SD}) ; \text { median }\end{array}$ & $\begin{array}{c}\text { Males } N=57 \text { mean } \\
(\mathrm{SD}) ; \text { median }\end{array}$ & $\begin{array}{c}\text { Student's } t \text {-test } P \\
\text { value }\end{array}$ & $\begin{array}{c}\text { All } N=126 \text { mean } \\
(\mathrm{SD}) ; \text { median }\end{array}$ \\
\hline Age $(\mathrm{range})$ & $38(10) ; 38(23-60)$ & $38(12) ; 36(19-64)$ & 0.730 & $38(11) ; 37$ \\
tHcy $(\mu \mathrm{mol} / \mathrm{L})$ & $8.4(1.8) ; 7.9$ & $9.7(2.1) ; 9.7$ & $<0.001$ & $8.9(2.1) ; 8.9$ \\
MMA $(\mathrm{nmol} / \mathrm{L})$ & $116(93) ; 101$ & $112(76) ; 100$ & 0.794 & $114(85) ; 100$ \\
Plasma 5-MTHF $(\mathrm{nmol} / \mathrm{L})$ & $19.4(8.5) ; 19.1$ & $18.7(8.2) ; 17.8$ & 0.624 & $19.1(8.3) ; 18.2$ \\
Redcell 5-MTHF $(\mathrm{nmol} / \mathrm{L})^{*}$ & $583(222) ; 572$ & $585(164) ; 557$ & 0.975 & $586(197) ; 560$ \\
Whole blood 5-MTHF $(\mathrm{nmol} / \mathrm{L})$ & $618(229) ; 592$ & $611(172) ; 582$ & 0.838 & $615(205) ; 584$ \\
\hline
\end{tabular}

${ }^{*}$ Result adjusted for plasma 5-MTHF content.

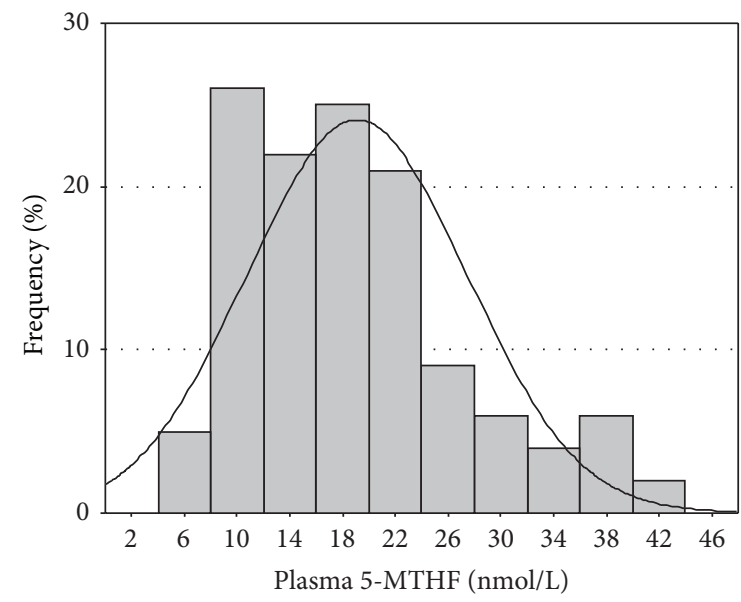

(a)

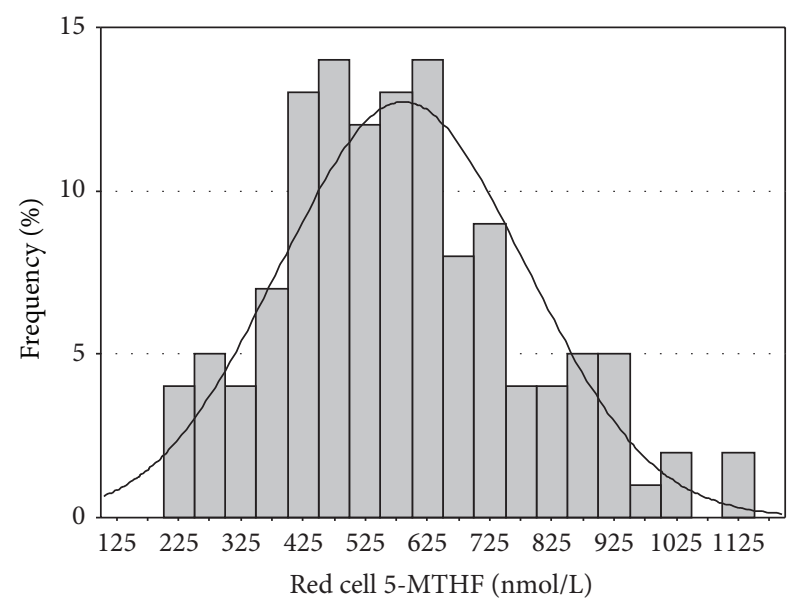

(b)

FIGURE 2: Distribution of the 5-MTHF concentrations in plasma and red cells.

tHcy were established as $13 \mu \mathrm{mol} / \mathrm{L}$ (females, $N=72$ ) and $15 \mu \mathrm{mol} / \mathrm{L}$ (males, $N=62$ ) and for MMA as $430 \mathrm{nmol} / \mathrm{L}$ (all 134 subjects).

3.2. Establishing Reference Intervals for 5-MTHF. Five subjects with functional deficiencies of folate and/or vitamin $\mathrm{B}_{12}$ as defined by elevated tHcy $(>13 \mu \mathrm{mol} / \mathrm{L}$ for females and $>15 \mu \mathrm{mol} / \mathrm{L}$ for males) and MMA (>430 nmol/L for both genders) were excluded from further analysis. In addition, three subjects had highly elevated red cells 5-MTHF of $>1143 \mathrm{nmol} / \mathrm{L}$ (identified by the Tukey test as outlying values) and these subjects were also excluded. There were no outlying plasma 5-MTHF values. Hence, 126 subjects were eligible for the construction of the reference intervals for 5-MTHF. The ethnic distribution of these 126 subjects was 93 Caucasian (73\%), 17 Afro-Caribbean (14\%), and 16 Asian (13\%). The proportion of women within these ethnic groups was $41 \%$ Caucasian, 65\% Afro-Caribbean, and 44\% Asian. The age and summary of all results for females and males used to derive 5 -MTHF reference intervals is given in Table 1 . Age and all the parameters measured followed a normal distribution. The values remained normally distributed after partition by sex. Reference intervals together with $90 \%$ confidence intervals for the lower and upper 95\% reference limits are displayed in Table 2. The distribution of 5-MTHF concentrations in plasma and red blood cells is shown in Figure 2. Plasma 5MTHF correlated with whole blood 5-MTHF $(r=0.565$,
TABLE 2: Reference intervals for 5-MTHF with $90 \%$ confidence intervals for lower and upper $95 \%$ reference limits.

\begin{tabular}{lccc}
\hline Analyte & $\begin{array}{c}\text { Reference } \\
\text { intervals }\end{array}$ & $\begin{array}{c}\text { Lower } \\
\text { reference } \\
\text { limit }\end{array}$ & $\begin{array}{c}\text { Upper } \\
\text { reference } \\
\text { limit }\end{array}$ \\
\hline Plasma 5-MTHF (nmol/L) & $6.6-39.9$ & $5.3-8.9$ & $36.9-41.7$ \\
$\begin{array}{l}\text { Redcell 5-MTHF (nmol/L) } \\
\begin{array}{l}\text { Whole blood 5-MTHF } \\
\text { (nmol/L) }\end{array}\end{array}$ & $223-1040$ & $206-291$ & $930-1110$ \\
\hline
\end{tabular}

$P<0.001)$, red cell 5-MTHF $(r=0.523, P<0.001)$ but did not correlate with age $(r=0.087, P=0.332)$, tHcy $(r=-0.122, P=0.172)$, or MMA $(r=-0.103, P=0.256)$. Red cell 5-MTHF correlated with whole blood 5-MTHF ( $r=$ $0.998, P<0.001)$ and age $(r=0.204, P=0.022)$ but did not correlate with tHcy $(r=-0.172, P=0.054)$ and MMA ( $r=-0.047, P=0.605)$. Whole blood 5-MTHF, in addition to its correlations with age, plasma, and red cell 5-MTHF, correlated with tHcy $(r=-0.181, P=0.043)$.

\section{Discussion}

Reference intervals of 5-MTHF were determined for plasma $(6.6-39.9 \mathrm{nmol} / \mathrm{L})$ and red cells $(223-1040 \mathrm{nmol} / \mathrm{L})$ for healthy adults aged 19-64 years. Separate reference intervals 
are also shown for the whole blood 5-MTHF which can be utilised if plasma 5-MTHF is not available to correct for red cell 5-MTHF contents. Many laboratories performing the standard RCF assay do not adjust their results for folate contents in plasma. Although this approach reduces assay costs, it may provide misleading RCF status, especially when plasma folate concentrations are $>45 \mathrm{nmol} / \mathrm{L} \mathrm{[26].}$

Subjects with likely functional folate and/or vitamin $\mathrm{B}_{12}$ deficiency/insufficiency were excluded from the construction of 5-MTHF reference intervals after the determination of cohort specific upper limits for plasma tHcy and MMA. The upper limits for plasma tHcy and MMA were established prior to removal of six subjects who on subsequent review were discovered to be taking previously nondeclared medications or supplements and four subjects with outlying tHcy and/or MMA values. This process is in agreement with expert recommendations [27]. The value for the upper reference limit for tHcy of $13 \mu \mathrm{mol} / \mathrm{L}$ for females and $15 \mu \mathrm{mol} / \mathrm{L}$ for males established in our current study is similar to the upper limits of 12.8 and $14.7 \mu \mathrm{mol} / \mathrm{L}$ observed for females and males, respectively (nonsmokers aged 40-42 years with high folate intakes and low-moderate coffee consumption), resident in western Norway [28]. The difference of $2 \mu \mathrm{mol} / \mathrm{L}$ between the upper $\mathrm{tHcy}$ reference limit for females and males is consistent with a study reported by Jacques et al. [29]. Although it has been well documented that tHcy is influenced by gender and age [29], laboratories often still choose to adopt a single cutoff value to distinguish normal from elevated tHcy concentrations.

The measurement of plasma MMA is accepted as a sensitive functional marker of cobalamin deficiency/insufficiency and avoids the ambiguities associated with commonly used serum cobalamin assays [13]. As with tHcy, the upper limit above which an MMA concentration is considered to be elevated differs between laboratories [30] and a variety of approaches to determine reference intervals have been used. For example, Rasmussen et al. [31] reported an inner 95\% reference intervals for MMA of 80-280 nmol/L established in 235 subjects prior to exclusion of those with a high probability of cobalamin deficiency (based on MMA decrease post cobalamin supplementation), outliers and those with high tHcy. In another study, an MMA concentration $>470 \mathrm{nmol} / \mathrm{L}$ (inner 95\%) was used as the upper limit in healthy adults with no clinical laboratory evidence of cobalamin deficiency [32].

Population-based reference intervals for 5-MTHF have not previously been reported. We are therefore unable to compare our findings with those of others. However the values for 5-MTHF concentrations obtained are in good agreement with data from other studies $[6,33]$. In comparison with the median of $427 \mathrm{nmol} / \mathrm{L}$ (range: 92-1086) for red cell 5-MTHF from 109 healthy subjects, aged 18-65 years, reported by Smulders et al. [8], the values in our study were higher: median $560 \mathrm{nmol} / \mathrm{L}$ (range: 206-1110). This might be attributed to differences in methodologies and the fact that individuals with mild to moderate B-vitamin deficiencies were not excluded in that study [8].

A positive correlation between red cell 5-MTHF concentrations and age observed in this study is consistent with previous observations $[34,35]$. Conversely, higher red cell
5-MTHF values in older participants are not reflected by a corresponding decrease in tHcy levels, suggesting that age is a folate-independent determinant of tHcy. It is not clear why folate concentrations are higher in the elderly. It has been suggested that this could represent an oversupply of the vitamin (diet) or it could reflect the tendency, as opposed to the younger group, to retain folate both in plasma and red blood cells [35]. Surprisingly, plasma 5-MTHF did not correlate with tHcy in our selected cohort used to establish 5-MTHF reference intervals. However, the whole blood 5MTHF correlated weakly with tHcy $(P=0.043)$ and correlations of red cell 5-MTHF with tHcy were approaching statistical significance $(P=0.054)$. These weak or lack of correlations may be attributed to the relatively small sample size and the fact that all subjects with outlying tHcy and above our reference cutoffs were removed. To support this, Spearman's correlations (data not shown) on all subjects initially recruited $N=144$ demonstrated stronger and expected significant correlations of plasma or red cell (whole blood) 5-MTHF with tHcy.

One caveat to our study is that the 5-MTHF reference intervals are unlikely to apply to children. Opladen et al. reported that serum 5-MTHF levels are the highest in the first year of life, followed by a continuous decrease until the age of 16 years [36].

\section{Conclusions}

In conclusion, the plasma and red cell 5-MTHF reference intervals for an adult population were determined from 126 subjects without evidence of functional folate and/or vitamin $\mathrm{B}_{12}$ deficiency as assessed by tHcy and MMA analyses. The application of these intervals will assist in the evaluation of folate status and facilitate the evaluation of 5-MTHF as an independent risk factor for disease states.

\section{Ethical Approval}

The study was approved by St. Thomas' Hospital Local Research Ethics Committee and written consent was obtained from all participants, no. 07/H0804/148.

\section{Conflict of Interests}

The authors declare that there is no conflict of interests regarding the publication of this paper.

\section{Acknowledgments}

The authors would like to thank Mrs. Renata Gorska (Centre for Haemostasis and Thrombosis) for preparation of the figures.

\section{References}

[1] H. McNulty, K. Pentieva, L. Hoey, and M. Ward, "Homocysteine, B-vitamins and CVD," Proceedings of the Nutrition Society, vol. 67, no. 2, pp. 232-237, 2008. 
[2] K. S. McCully, "Homocysteine, vitamins, and vascular disease prevention," The American Journal of Clinical Nutrition, vol. 86, no. 5, pp. 1563S-1568S, 2007.

[3] C. Antoniades, C. Shirodaria, N. Warrick et al., "5-methyltetrahydrofolate rapidly improves endothelial function and decreases superoxide production in human vessels: effects on vascular tetrahydrobiopterin availability and endothelial nitric oxide synthase coupling," Circulation, vol. 114, no. 11, pp. 1193-1201, 2006.

[4] I. Quéré, T. V. Perneger, J. Zittoun et al., "Red blood cell methylfolate and plasma homocysteine as risk factors for venous thromboembolism: a matched case-control study," The Lancet, vol. 359, no. 9308, pp. 747-752, 2002.

[5] R. J. Leeming, A. Pollock, L. J. Melville, and C. G. B. Hamon, "Measurement of 5-methyltetrahydrofolic acid in man by highperformance liquid chromatography," Metabolism, vol. 39, no. 9, pp. 902-904, 1990 .

[6] C. M. Pfeiffer, Z. Fazili, L. McCoy, M. Zhang, and E. W. Gunter, "Determination of folate vitamers in human serum by stableisotope-dilution tandem mass spectrometry and comparison with radioassay and microbiologic assay," Clinical Chemistry, vol. 50, no. 2, pp. 423-432, 2004.

[7] Z. Fazili and C. M. Pfeiffer, "Measurement of folates in serum and conventionally prepared whole blood lysates: application of an automated 96-well plate isotope-dilution tandem mass spectrometry method," Clinical Chemistry, vol. 50, no. 12, pp. 2378-2381, 2004.

[8] Y. M. Smulders, D. E. C. Smith, R. M. Kok et al., "Red blood cell folate vitamer distribution in healthy subjects is determined by the methylenetetrahydrofolate reductase C677T polymorphism and by the total folate status," The Journal of Nutritional Biochemistry, vol. 18, no. 10, pp. 693-699, 2007.

[9] F. M. T. Loehrer, C. P. Angst, W. E. Haefeli, P. P. Jordan, R. Ritz, and B. Fowler, "Low whole-blood S-adenosylmethionine and correlation between 5-methyltetrahydrofolate and homocysteine in coronary artery disease," Arteriosclerosis, Thrombosis, and Vascular Biology, vol. 16, no. 6, pp. 727-733, 1996.

[10] M. Lucock and Z. Yates, "Measurement of red blood cell methylfolate," The Lancet, vol. 360, no. 9338, pp. 1021-1022, 2002.

[11] Food and Nutrition Board IoM, Dietary Reference Intakes for Thiamin, Riboflavin, Niacin, Vitamin $B_{6}$, Folate, Vitamin $B_{12}$, Pantothenic Acid, Biotin and Choline, National Academy Press, Washington, DC, USA, 1998.

[12] UK NEQAS Haematinics, "Report on reference range data collected from haematinics scheme participants in July 2007," Tech. Rep., Good Hope Hospital, Haematology Department, Heart of England Foundation Trust, 2008.

[13] G. Hølleland, J. Schneede, P. M. Ueland, P. K. Lund, H. Refsum, and S. Sandberg, "Cobalamin deficiency in general practice. Assessment of the diagnostic utility and cost-benefit analysis of methylmalonic acid determination in relation to current diagnostic strategies," Clinical Chemistry, vol. 45, no. 2, pp. 189198, 1999.

[14] P. J. Babidge and W. J. Babidge, "Determination of methylmalonic acid by high-performance liquid chromatography," Analytical Biochemistry, vol. 216, no. 2, pp. 424-426, 1994.

[15] A. Sobczynska-Malefora, D. J. Harrington, M. C. E. Lomer et al., "Erythrocyte folate and 5-methyltetrahydrofolate levels decline during 6 months of oral anticoagulation with warfarin," Blood Coagulation and Fibrinolysis, vol. 20, no. 4, pp. 297-302, 2009.
[16] J. Chladek, L. Sispera, and J. Martinkova, "High-performance liquid chromatographic assay for the determination of 5methyltetrahydrofolate in human plasma," Journal of Chromatography B, vol. 744, pp. 307-313, 2000.

[17] H. Ihara, T. Watanabe, N. Hashizume et al., "Commutability of National Institute of Standards and Technology standard reference material 1955 homocysteine and folate in frozen human serum for total folate with automated assays," Annals of Clinical Biochemistry, vol. 47, no. 6, pp. 541-548, 2010.

[18] A. V. Hoffbrand, F. A. Newcombe, and D. L. Mollin, "Method of assay of red cell folate activity and the value of the assay as a test for folate deficiency," Journal of Clinical Pathology, vol. 19, no. 1, pp. 17-28, 1966.

[19] CLSI, Defining, Establishing, and Verifying Reference Intervals in the Clinical Laboratory, Approved Guideline, CLSI document C28-A3, Clinical and Laboratory Standards Institute, Wayne, Pa, USA, 3rd edition, 2008.

[20] J. W. Tukey, Exploratory Data Analysis, Addison-Wesley, Reading, Mass, USA, 1977.

[21] E. K. Harris and J. C. Boyd, "On dividing reference data into subgroups to produce separate reference ranges," Clinical Chemistry, vol. 36, no. 2, pp. 265-270, 1990.

[22] H. E. Solberg, "International Federation of Clinical Chemistry (IFCC). Scientific Committee, Clinical Section. Expert Panel on Theory of Reference Values, and International Committee for Standardization in Haematology (ICSH). Standing Committee on Reference Values. Approved Recommendation (1986) on the theory of reference values. Part 1 . The concept of reference values," Journal of Clinical Chemistry and Clinical Biochemistry, vol. 25, no. 5, pp. 337-342, 1987.

[23] E. H. Reynolds, R. J. Wrighton, A. L. Johnson, J. Preece, and I. Chanarin, "Inter-relations of folic acid and vitamin $\mathrm{B}_{12}$ in drugtreated epileptic patients," Epilepsia, vol. 12, no. 2, pp. 165-171, 1971.

[24] W.-Y. Au, S.-K. Tsang, B. K. L. Cheung, T.-S. Siu, E. S. K. Ma, and S. Tam, "Cough mixture abuse as a novel cause of folate deficiency: a prospective, community-based, controlled study," Haematologica, vol. 92, no. 4, pp. 562-563, 2007.

[25] U. Sener, Y. Zorlu, O. Karaguzel, O. Ozdamar, I. Coker, and M. Topbas, "Effects of common anti-epileptic drug monotherapy on serum levels of homocysteine, vitamin $\mathrm{B}_{12}$, folic acid and vitamin B6," Seizure, vol. 15, no. 2, pp. 79-85, 2006.

[26] N. Philpott, B. P. Kelleher, O. P. Smith, and S. D. O'Broin, "High serum folates and the simplification of red cell folate analysis," Clinical and Laboratory Haematology, vol. 23, no. 1, pp. 15-20, 2001.

[27] H. Refsum, A. D. Smith, P. M. Ueland et al., "Facts and recommendations about total homocysteine determinations: an expert opinion," Clinical Chemistry, vol. 50, no. 1, pp. 3-32, 2004.

[28] O. Nygård, H. Refsum, P. M. Ueland, and S. E. Vollset, "Major lifestyle determinants of plasma total homocysteine distribution: the hordaland homocysteine study," The American Journal of Clinical Nutrition, vol. 67, no. 2, pp. 263-270, 1998.

[29] P. F. Jacques, I. H. Rosenberg, G. Rogers et al., "Serum total homocysteine concentrations in adolescent and adult Americans: results from the third National Health and Nutrition Examination Survey," The American Journal of Clinical Nutrition, vol. 69, no. 3, pp. 482-489, 1999.

[30] E. Nexo and E. Hoffmann-Lücke, "Holotranscobalamin, a marker of vitamin B-12 status: analytical aspects and clinical utility," The American Journal of Clinical Nutrition, vol. 94, no. 1, pp. 359S-365S, 2011. 
[31] K. Rasmussen, J. Moller, M. Lyngbak, A. M. Pedersen, and L. Dybkjaer, "Age- and gender-specific reference intervals for total homocysteine and methylmalonic acid in plasma before and after vitamin supplementation," Clinical Chemistry, vol. 42, pp. 630-636, 1996.

[32] A. Goringe, R. Ellis, I. McDowell et al., "The limited value of methylmalonic acid, homocysteine and holotranscobalamin in the diagnosis of early $\mathrm{B}_{12}$ deficiency," Haematologica, vol. 91, no. 2, pp. 231-234, 2006.

[33] Z. Fazili, C. M. Pfeiffer, and M. Zhang, "Comparison of serum folate species analyzed by LC-MS/MS with total folate measured by microbiologic assay and Bio-Rad radioassay," Clinical Chemistry, vol. 53, no. 4, pp. 781-784, 2007.

[34] J. D. Wright, K. Bialostosky, E. W. Gunter et al., "Blood folate and vitamin $\mathrm{B}_{12}$ : United States, 1988-94," Vital and Health Statistics, no. 243, pp. 1-78, 1998.

[35] J. Selhub, P. F. Jacques, G. Dallal, S. Choumenkovitch, and G. Rogers, "The use of blood concentrations of vitamins and their respective functional indicators to define folate and vitamin $\mathrm{B}_{12}$ status," Food and Nutrition Bulletin, vol. 29, no. 2, pp. S67-S73, 2008.

[36] T. Opladen, V. T. Ramaekers, G. Heimann, and N. Blau, "Analysis of 5-methyltetrahydrofolate in serum of healthy children," Molecular Genetics and Metabolism, vol. 87, no. 1, pp. 61-65, 2006. 


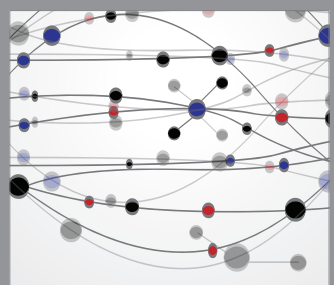

The Scientific World Journal
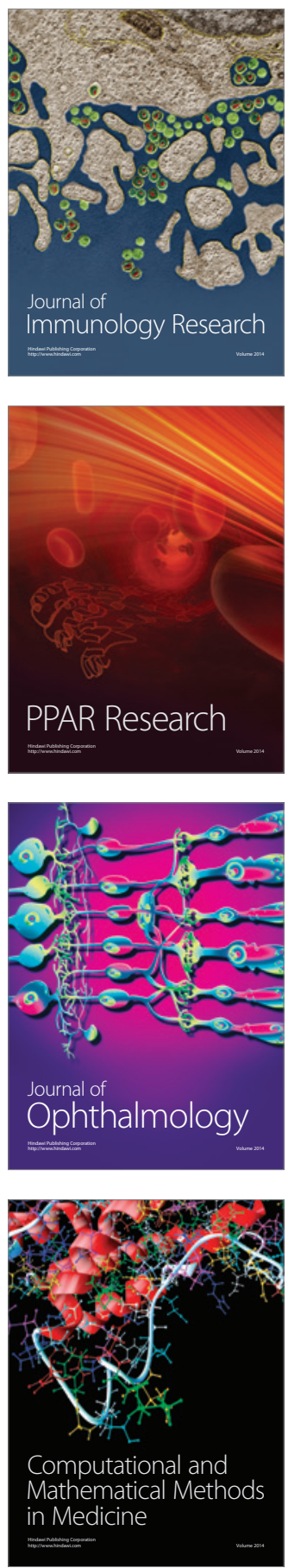

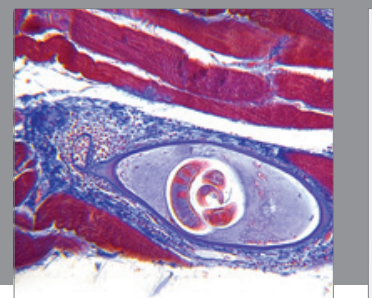

Gastroenterology

Research and Practice
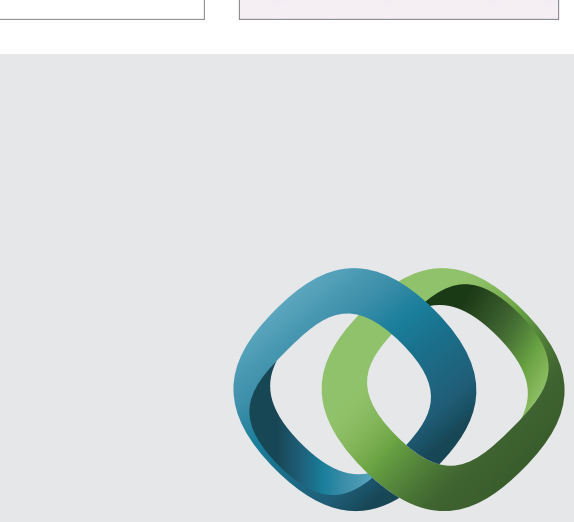

\section{Hindawi}

Submit your manuscripts at

http://www.hindawi.com
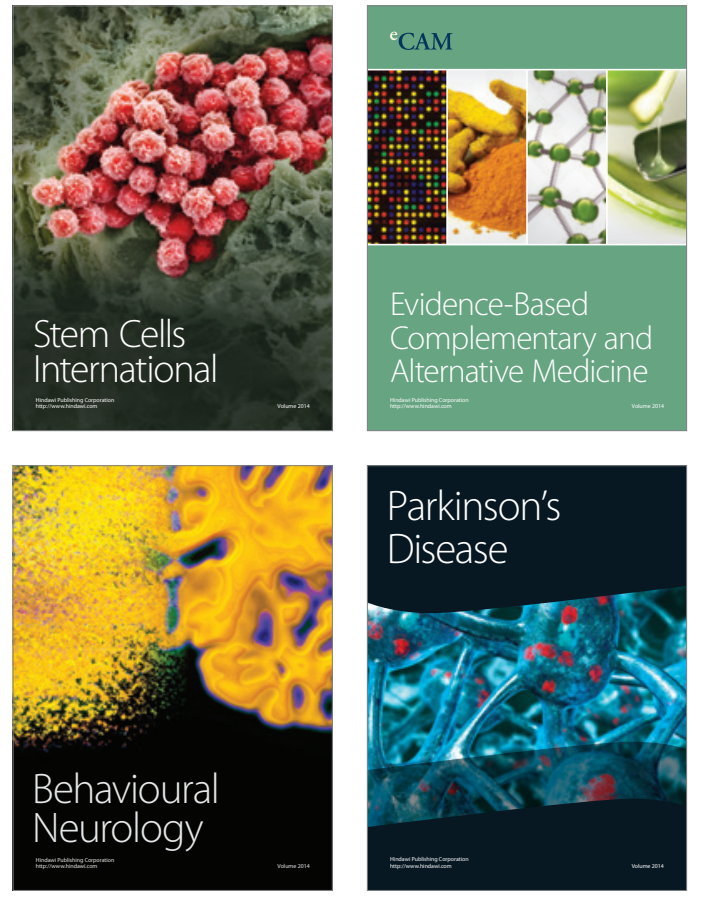
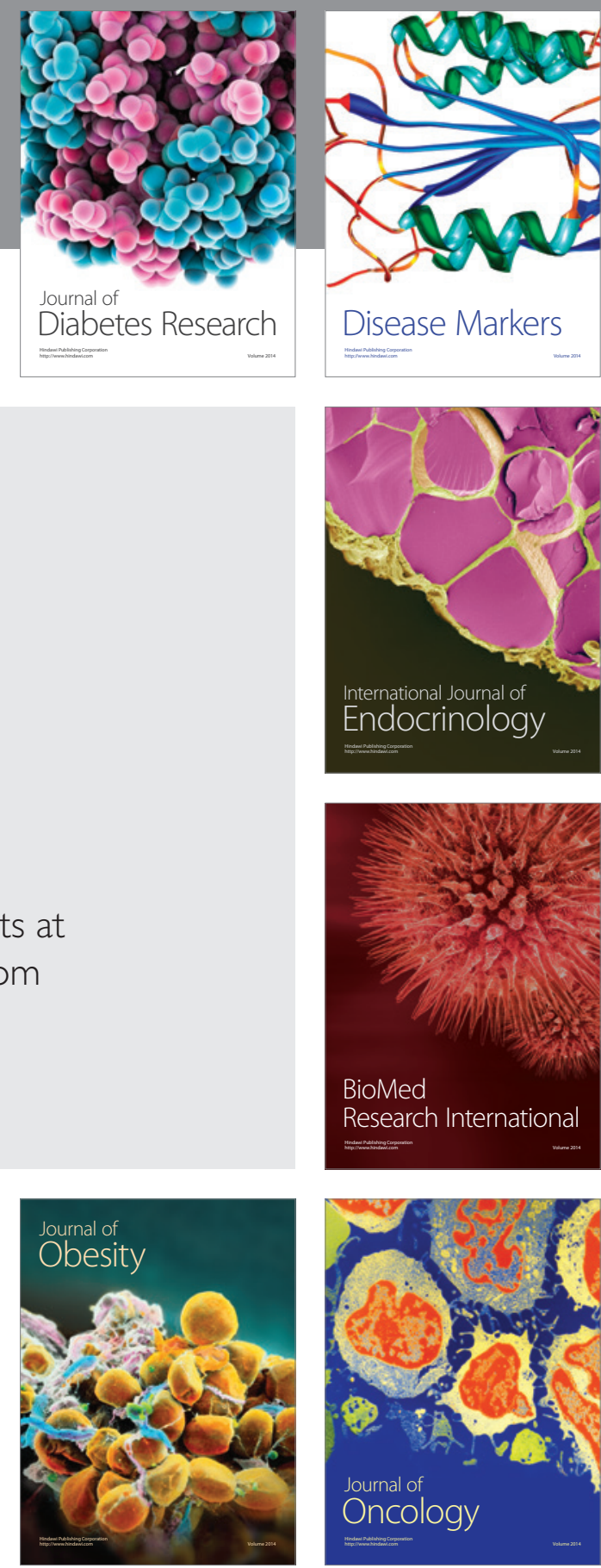

Disease Markers
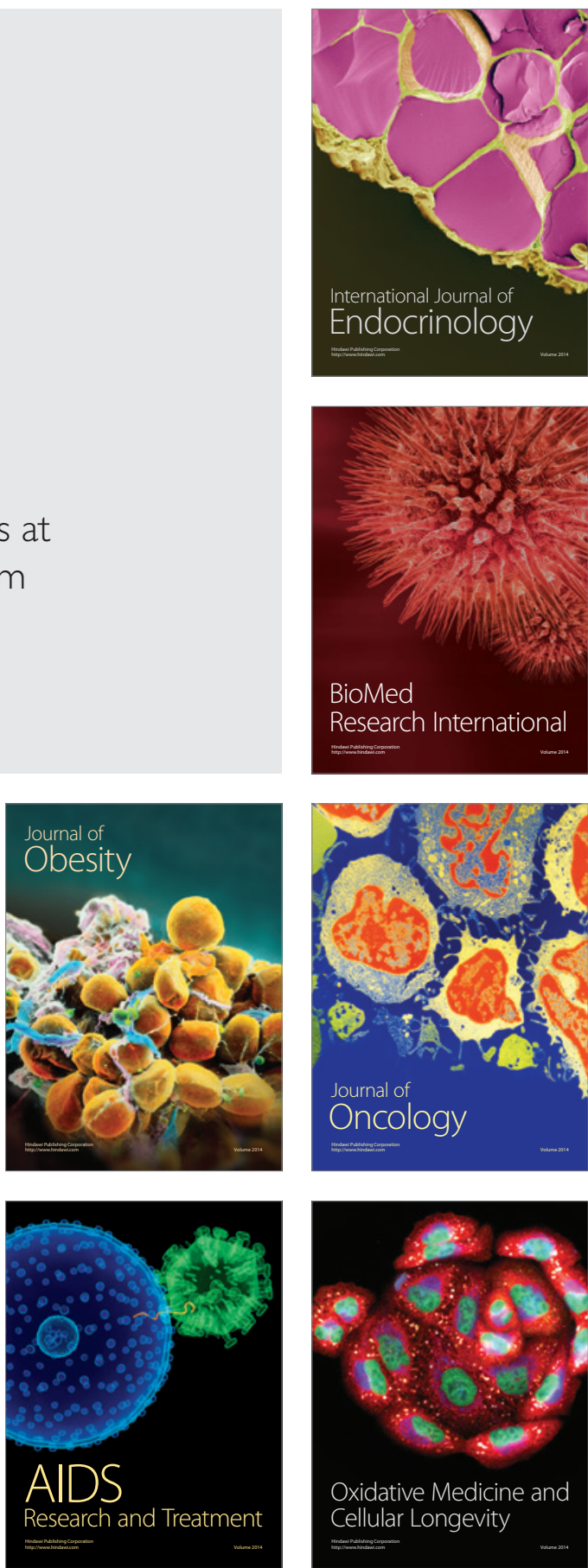